\title{
Simultaneous high- and low-latitude reconnection: ESR and DMSP observations
}

\author{
F. Pitout ${ }^{1,2}$, P. T. Newell ${ }^{3}$, and S. C. Buchert ${ }^{1}$ \\ ${ }^{1}$ Swedish Institute of Space Physics, Box 537, 75121 Uppsala, Sweden \\ ${ }^{2}$ Centre d'Etude Spatiale des Rayonnements, 9 avenue du Colonel Roche, F-31028 Toulouse Cedex 4, France \\ ${ }^{3}$ John Hopkins University, Applied Physics Laboratory, 11100 John Hopkins Road, Laurel MD - 20723-6099, USA
}

Received: 11 October 2001 - Revised: 27 February 2002 - Accepted: 15 March 2002

\begin{abstract}
We present EISCAT Svalbard Radar and DMSP observations of a double cusp during an interval of predominantly northward IMF on 26 November 2000. In the cusp region, the ESR dish, pointing northward, recorded sunward ionospheric flow at high latitudes (above $82^{\circ} \mathrm{GL}$ ), indicating reconnection occuring in the magnetospheric lobe. Meanwhile, the same dish also recorded bursts of poleward flow, indicative of bursty reconnection at the subsolar magnetopause. Within this time interval, the DMSP F13 satellite passed in the close vicinity of the Svalbard archipelago. The particle measurement on board exhibited a double cusp structure in which two oppositely oriented ion dispersions are recorded. We interpret this set of data in terms of simultaneous merging at low- and high-latitude magnetopause. We discuss the conditions for which such simultaneous highlatitude and low-latitude reconnection can be anticipated. We also discuss the consequences of the presence of two X-lines in the dayside polar ionosphere.
\end{abstract}

Key words. Magnetospheric physics (solar wind-magnetosphere interactions) - Ionosphere (polar ionosphere; plasma convection)

\section{Introduction}

It is nowadays well accepted that solar wind particles manage to go through the Earth's magnetopause, thanks to the reconnection process. Interplanetary Magnetic Field (IMF) lines merge with field lines of the Earth's magnetosphere. The particles subsequently penetrate into the magnetosphere, and some of them even precipitate into the high-latitude dayside ionosphere through the cusp region. The location of the reconnection site at the magnetopause is highly dependent on the external IMF conditions. The location of the cusp region and therefore its ionospheric footprint, in turn, depend on the location of the reconnection site. The dynamics of the cusp's open field lines is rather complex, and for simplicity, most

Correspondence to: F. Pitout (fp@irfu.se) published studies deal with the cusp under steady IMF conditions, i.e. either northward or southward IMF.

For southward IMF, the literature abounds with case studies of the ionospheric response to low-latitude reconnection at the sub-solar magnetopause. The sporadic nature of the reconnection process at the magnetopause and its response in the ionosphere are very well documented. Pulsed reconnection at the magnetopause means pulsed precipitation of low energy electrons in the dayside polar ionosphere, producing quasi-periodic electron density and temperature enhancements in the F-region. Besides, the electric field is usually very high in the cusp region. The ionospheric plasma convection is strongly poleward there, often reaching several $\mathrm{km} / \mathrm{s}$. Due to this fast poleward flow, the manifestations of pulsed reconnection in the polar dayside ionosphere are pulsed flow channels, as observed by HF radars, poleward moving auroral forms, as observed by optical instruments (e.g. Thorolfsson et al., 2000) and poleward moving plasma of enhanced electron density and temperature, as observed by incoherent scatter radars (e.g. Lockwood et al., 2001).

When the IMF points northward, things are somewhat different. The antiparallel criterion required between the IMF and the Earth's magnetic field lines is nominally met only at the high-latitude magnetopause, poleward of the cusp. The auroral display is then also sensitive to the pulsing nature of the reconnection process in the lobe (Sandholt et al., 1998c, 2001). However, recent observations of the northward IMF cusp by incoherent scatter radars showed no periodic or even quasi-periodic variations in the plasma parameters (Pitout et al., 2001). This is probably due to the weak sunward plasma convection velocity associated with lobe reconnection.

Even if the $Z$-component of the IMF does play a key role in the reconnection process, the $Y$-component should not be neglected as it is too often. In fact, the $Y$-component apart from being responsible for the symmetry or asymmetry of the convection pattern in the ionosphere, plays an important role in the reconnection process itself especially when the $Z$ component is weak. A strong IMF $B_{y}$ is thought to allow for reconnection at the far dusk or dawn sides of the magne- 
topause, even if the conditions are a priori not favorable.

Considering the classification of auroral forms by Sandholt et al. (1998a), the so-called type 1 aurora is associated with subsolar reconnection. Type 1 auroras are observed at typical cusp latitude for southward IMF (around $75^{\circ}$ MLAT). On the other hand, type 2 auroras, due to lobe merging, are located at higher latitudes and are consequently observed typically for northward IMF. However, cases of simultaneous observations of type 1 and type 2 auroral forms have been reported (Sandholt et al., 1998b, 2001). These so-called auroral bifurcations have been observed by using all-sky cameras. Their wide field of view makes it possible to observe the whole dayside aurora display and dynamics over a large region of the ionosphere. Those observations suggest that the reconnection process may take place simultaneously in some particular circumstances at the dayside magnetopause and in the magnetospheric lobe.

It was reported by Russell et al. (2000a, b) that reconnection could actually take place at the subsolar magnetopause even for northward IMF, when the solar wind dynamic pressure is high. It is thought that interplanetary magnetic field lines and the Earth's magnetopshere magnetic field lines may then merge even without strict antiparallel conditions.

Very recently, Wing et al. (2001) have reported observations of double cusp crossings by DMSP satellites and have proposed a model explaining those observations in term of low- and high-latitude merging occurring simultaneously. The model predicts the existence of two cusps, so to speak, one at high latitude and another at a lower latitude for a weak negative $Z$-component of the IMF and a strong $Y$ component. Within the higher latitude cusp, originating from the high-latitude magnetosheath, the $\boldsymbol{E} \times \boldsymbol{B}$ drift is thought to be poleward and strongly azimuthal, resulting in an ion dispersion that looks like a typical southward IMF dispersion. On the other hand, the lower latitude cusp is thought to be located in a region of weak azimuthal $\boldsymbol{E} \times \boldsymbol{B}$ drift. The lower latitude cusp appears, therefore, dispersionless.

To authors' knowledge, not a single case of double cusp observed by incoherent scatter radar has ever been reported. The EISCAT radar facilities available on Svalbard makes it possible to observe the polar ionosphere by pointing the steerable dish northward at low elevation. We present here such a case of double cusp observed by EISCAT Svalbard Radar.

\section{Observations}

\subsection{Interplanetary conditions}

The ACE spacecraft was located at $X_{\mathrm{GSE}}=225 R_{E}$ away from the Earth in the upstream solar wind. Considering an average solar wind speed of $460 \mathrm{~km} / \mathrm{s}$ throughout the period of interest, a time delay between the measurements at ACE and the response in the ionosphere of about $57 \mathrm{~min}$ is expected. This time lag can be confirmed thanks to the pressure pulse recorded at 07:03 UT at ACE and the IMAGE mag- netograms showing a strong response at 08:00 UT. Figure 1 shows the IMF recorded by ACE spacecraft for the interval 06:00-09:00 UT on 26 November 2000. Data have been lagged by the $57 \mathrm{~min}$. The first three panels, from top to bottom, show, respectively, the $X-, Y$ - and $Z$-components of the IMF in the GSM coordinate system, while the last panel shows the clock angle $\theta$ defined as follow: $\theta=\operatorname{atan}\left(\left|B_{y}\right| / B_{z}\right)$ if $B_{z}>0$ or $\theta=\pi-\operatorname{atan}\left(\left|B_{y}\right| / B_{z}\right)$ if $B_{z}<0$.

Before 07:10UT, the IMF points mainly southward and strongly dawnward. Between 07:10 and 08:00 UT, which is the time period we will focus on, the IMF is predominantly northward though with three southward incursions at 07:25, 07:37 and 07:51 UT. At 08:00 UT, a pressure pulse reaches the Earth. The associated IMF signature is obvious. The $Z$ component flips southward, the $Y$-component duskward and the $X$-component anti-sunward.

\subsection{EISCAT Svalbard radars}

The EISCAT Scientific Association has among others a twodish incoherent scatter radar system near Longyearbyen on Svalbard. One dish is fixed, pointing along the local magnetic field line, and the other is fully steerable towards any direction. The ESR data showed in this study are postintegrated with a time resolution of $128 \mathrm{~s}$.

Let us first focus on the steerable antenna. On 26 November 2000, it was pointing towards geographic north (azimuth $0^{\circ}$ ) at low elevation $\left(30^{\circ}\right)$. Figure 2 displays the data from the two radars: the steerable $32 \mathrm{~m}$-dish (Fig. 2a) and the fixed $42 \mathrm{~m}$-dish (Fig. 2b) with, from top to bottom, electron density, electron temperature, ion temperature and ion velocity, along the line of sight (positive velocities away from the radar). A quick look at the velocity data (bottom panel of the Fig. 2a) allows us to separate two regions of interest within the time period 07:10-08:00 UT: above $82^{\circ} \mathrm{GL}$, where the plasma flow is clearly sunward and below $82^{\circ}$ Geographic Latitude (GL), where the plasma flow exhibits strong antisunward flow channels. We will first deal with those two regions separately, since they exhibit a priori completely different behavior and dynamics.

At high latitudes, i.e. above $82^{\circ} \mathrm{GL}$, the plasma flow has clearly a sunward component between 07:10 and 08:05 UT. The plasma velocity reaches at times $500 \mathrm{~m} / \mathrm{s}$, which is quite large for a reverse convection velocity. The density measurements indicate a density of $3 \cdot 10^{11} \mathrm{~cm}^{-3}$ between $82^{\circ}$ and $84^{\circ} \mathrm{GL}$. The electron temperature ranging from about 1500 up to $2000 \mathrm{~K}$, is slightly higher than in the close vicinity. Knowing that the dish points at $30^{\circ}$ of elevation, these latitudes correspond to actual altitudes of $200-300 \mathrm{~km}$, it is, therefore, the F-region which is observed in this range of latitudes. This clearly suggests that low energy electrons precipitate in this region of sunward plasma flow. No structures are observed either in the electron density or temperature.

At lower latitudes, below $82^{\circ} \mathrm{GL}$, the panels of the same Fig. 2a show a totally different view. The electron density is dramatically lower, the electron temperature appears more structured, as well as the ion temperature, and most obvious 

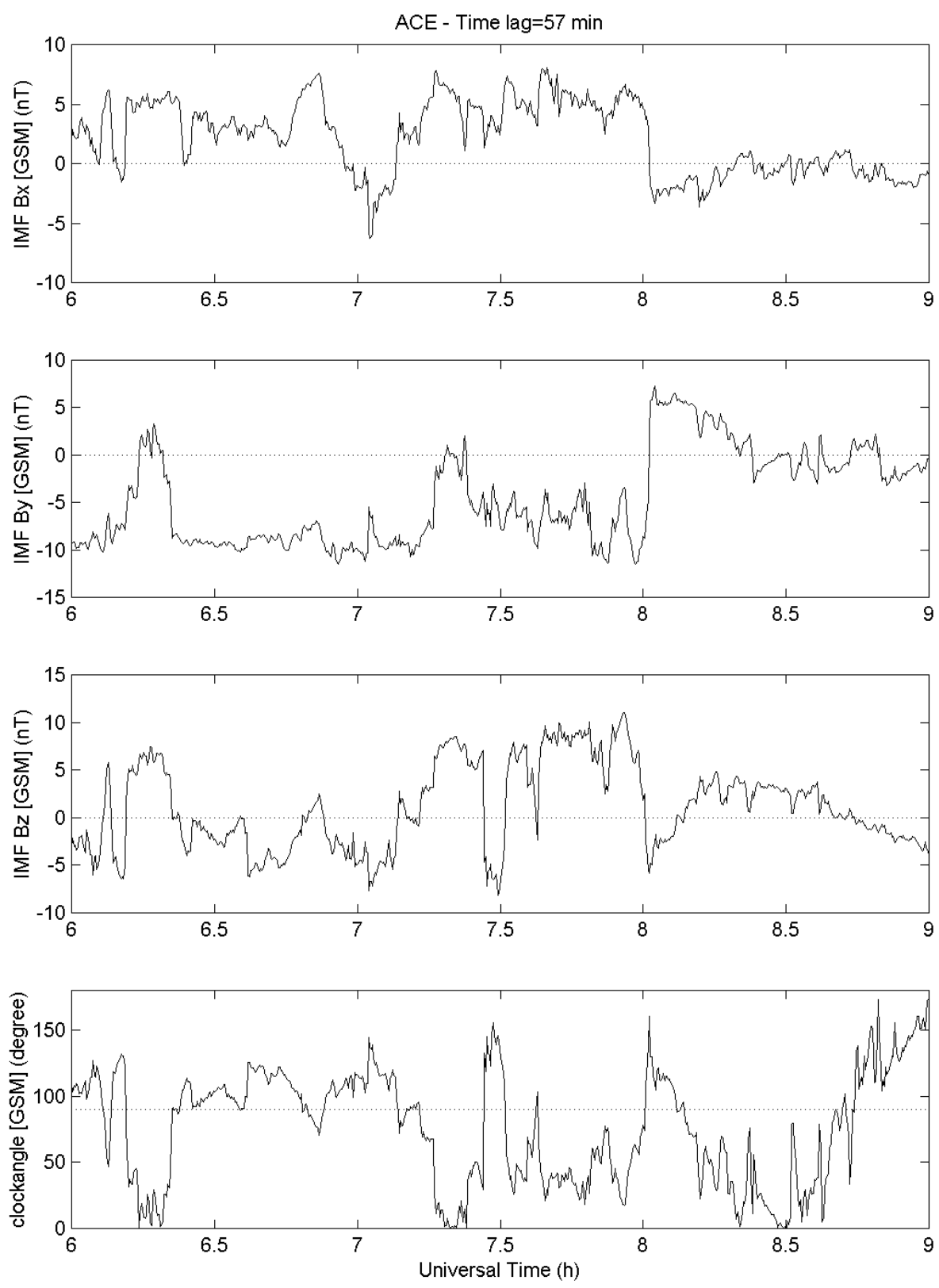

Fig. 1. Interplanetary Magnetic Field in GSM coordinates measured by ACE. Data lagged by 57 min. From top to bottom, $X$-, $Y$-, $Z$ component and clock angle.

of all, the plasma velocity is anti-sunward and highly variable.

Three flow channels are identified (black lines in Fig. 2a). They are clearly associated with ion heating due to frictional heating with the neutrals driven by high electric field. The measured component of the plasma velocity within the flow channels reaches $1000 \mathrm{~m} / \mathrm{s}$. In terms of convection electric field, it corresponds to about $50 \mathrm{mV} / \mathrm{m}$. Within those structures, the ionospheric plasma experiences electron heating and less obvious electron density enhancement. It is not easy to time those transients since they are moving. Nevertheless, we can try to time those at a common space reference, namely the latitude of the radars. By continuing the struc- tures down to $78^{\circ}$ of latitude (black lines in Fig. 2a), we obtain a useable timing. The two first flow channels must have passed over Longyearbyen at 07:05 and 07:25 UT, respectively. It is, however, less evident that the third actually comes from such a low latitude.

The second ESR dish records the ionospheric plasma parameters along the field line. Data are shown in Fig. $2 \mathrm{~b}$ from 06:00 through to 09:00 UT as a function of time and altitude. The electron density and temperature panels exhibit the usual characteristics of the dayside polar ionosphere. Electron density is high and well structured in the F-region, whereas the E-region looks empty. This is due to the low energy of the precipitating electrons. The reader should note that the low 


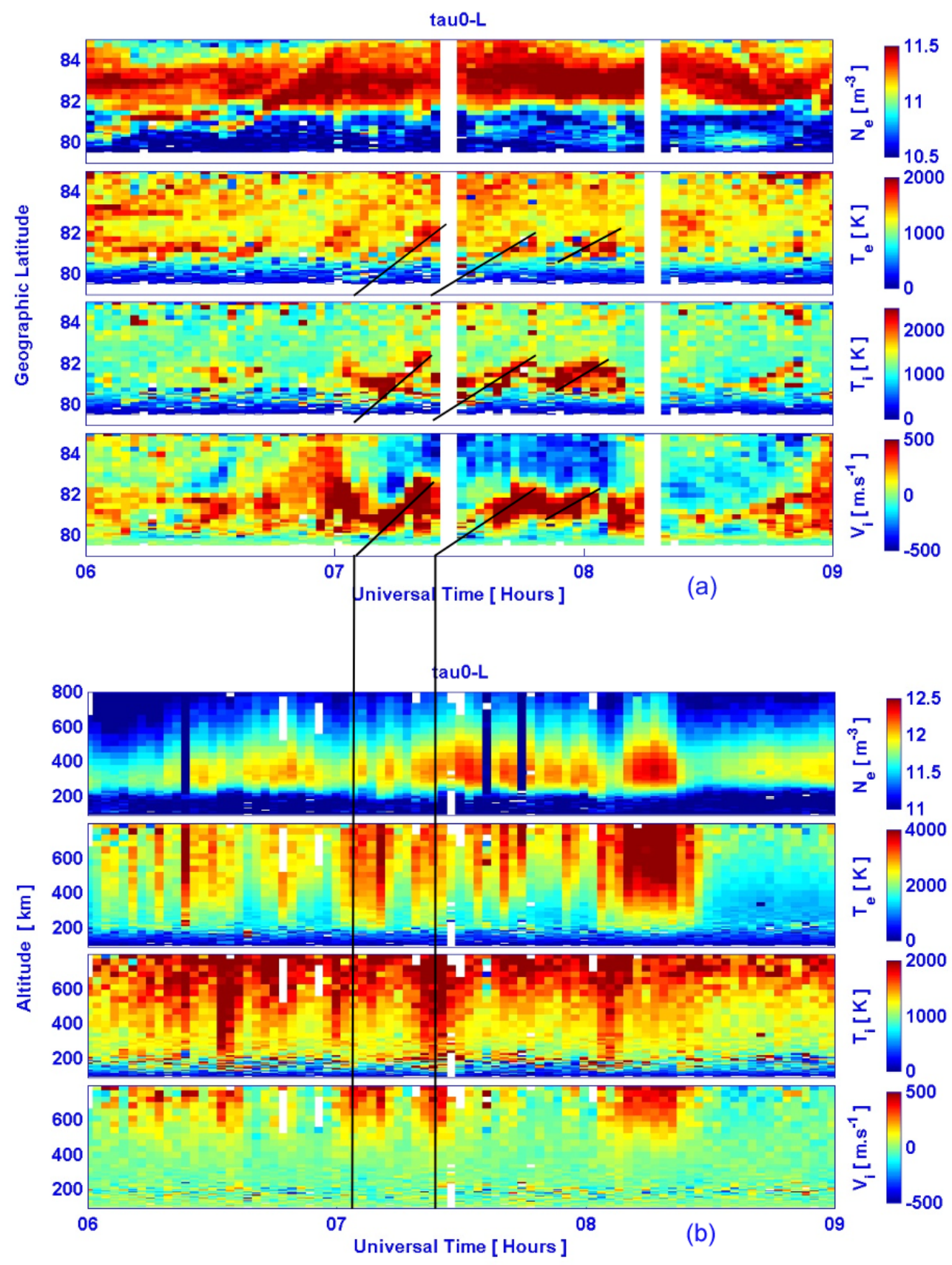

Fig. 2. Plasma parameters measured by the northward pointing ESR dish and the field-aligned dish on 26 November 2000 . From top to bottom: $N_{e}$, electron density, $T_{e}$, electron temperature, $T_{i}$, ion temperature, and line-of-sight velocity, $V_{i}$ (positive away from the radar) as a function of time and geographic latitude (a) or altitude (b).

energy electrons are effective in (1) heating the electron population in the ionosphere and as a consequence (2) in triggering ion outflow.

Let us focus on the third panel of Fig. 2b, which shows ion temperature, since the latter is a good indicator of electric field. There are three ion temperature/electric field enhancements: 07:05, 07:25, 08:00 UT. The first two structures clearly correspond to two intervals of southward IMF.
The third and last one is associated with the pressure pulse/southward turning of 08:00 UT.

\subsection{IMAGE magnetometers}

IMAGE (International Monitor for Auroral Geomagnetic Effects) consists of 27 magnetometer stations covering geographic latitudes from $58^{\circ}$ to $79^{\circ}$ degrees across Scandinavia 

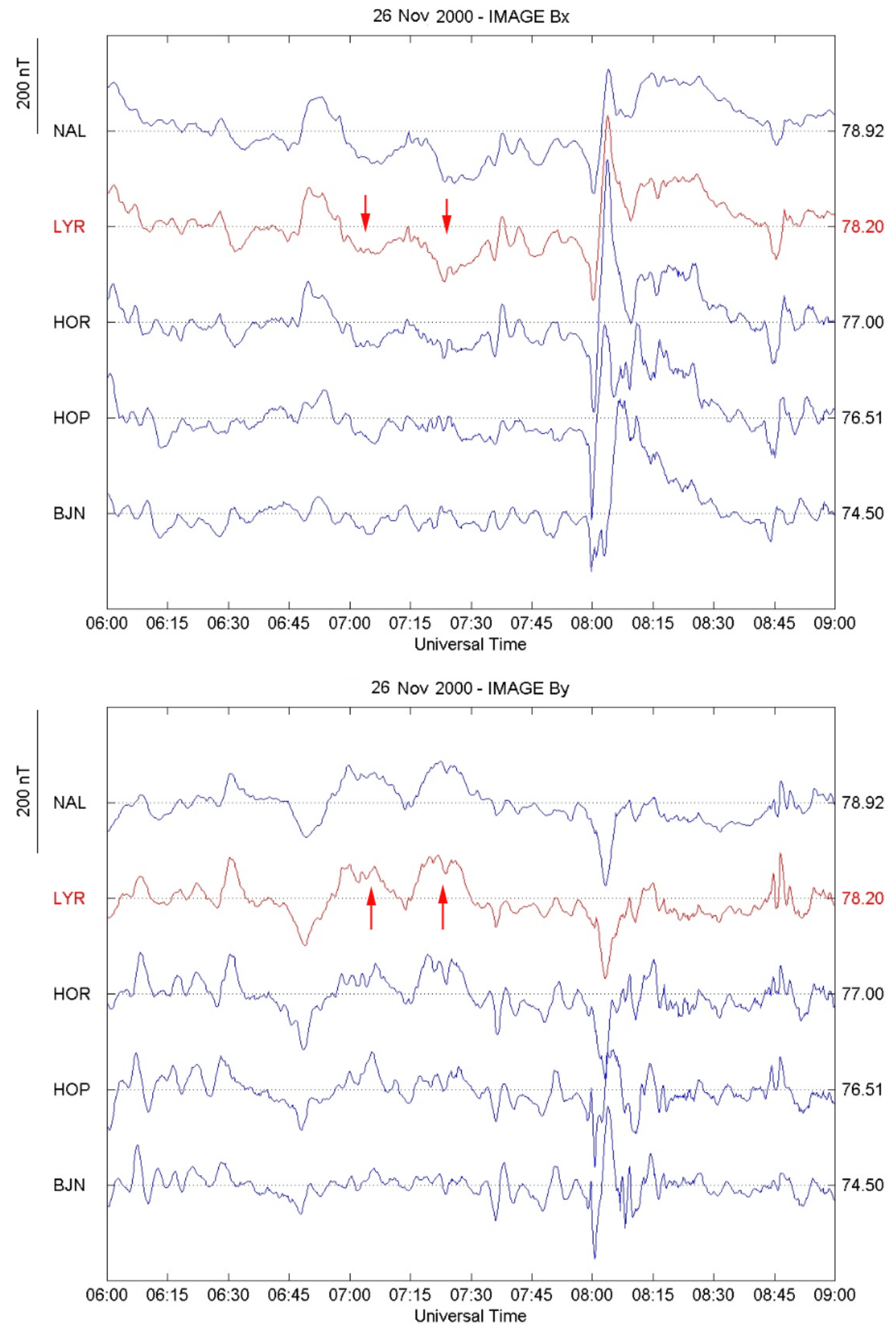

Fig. 3. Stack plot of the $X$ - and $Y$-components of the ground magnetic field recorded at the following IMAGE stations: Ny Ålesund (NAL), Longyearbyen (LYR), Hornsund (HOR), Hopen Island (HOP) and Bear Island (BJN).

(Viljanen and Häkkinen, 1997). We use here the five northernmost stations of the chain. Those five stations cover a small region between 74.50 and $78.92^{\circ}$ GL north and especially south of the ESR. The coverage is, therefore, complete, with the steerable ESR dish observing northward, the fixed ESR dish observing field-aligned and IMAGE recording south of the ESR. Also, the station in Ny Ålesund (NAL) fills the gap that exists between the coverages of the two radars. The $X$ - and $Y$-geographical components (respectively north and east) of the ground magnetic field recorded 


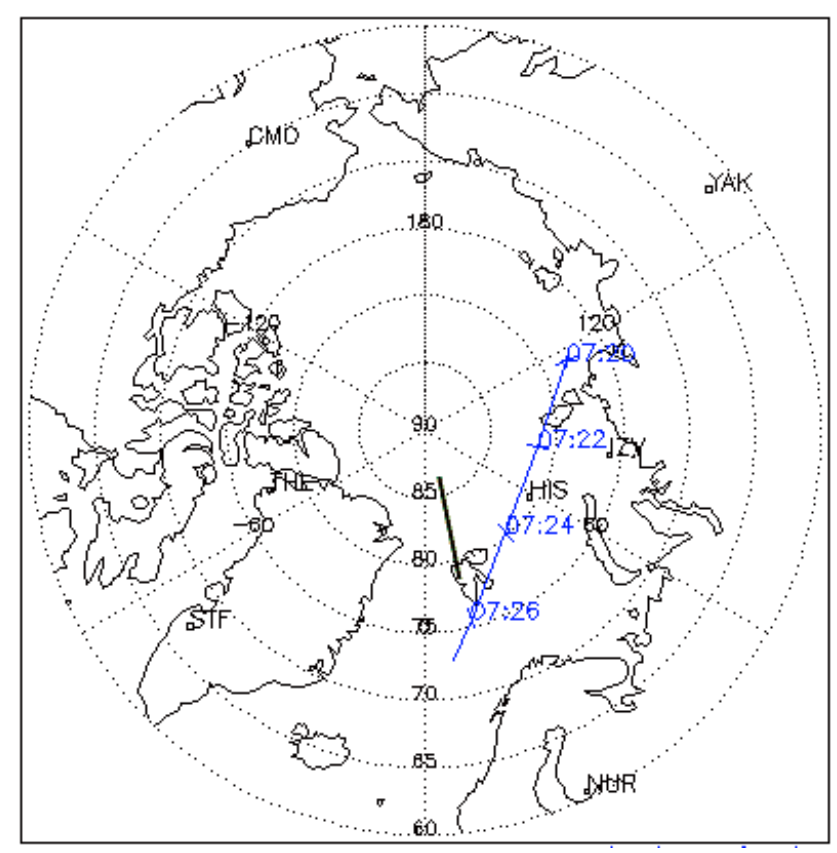

Fig. 4. Map over the northern polar cap showing the F13 footprint between 07:20 and 07:27 UT, as well as the field of view of the 32meter ESR dish.

by IMAGE are shown in Fig. 3.

Between 07:00 and 08:00 UT, the $X$-component of the ground magnetic field recorded at Ny Ålesund (NAL) and Longyearbyen (LYR) is predominantly negative. In terms of equivalent ionospheric Hall current, this corresponds to a westward current, which, in turn, corresponds to an eastward plasma flow. This is quite consistent with the negative $Y$-component of the IMF.

A closer look reveals enhancements of the $X$ - and $Y$ components around 07:05 and 07:25 UT (marked by red arrows on Fig. 4), which means that the plasma flow, in these time intervals, became accelerated northward and eastward. This is fully consistent with the ion heating events recorded by the field-aligned ESR antenna. There is no clear evidence of northward propagation of those Hall current intensifications. This is very likely due to the fact that the plasma flow is northward, but most of all strongly eastward (IMF $B_{y}<0$ ). Besides, LYR and NAL stations are rather close to each other in terms of latitudinal separation.

\subsection{DMSP-F13 spacecraft overpass}

On 26 November 2001, the F13 satellite flew slightly east of Svalbard from north to south (Fig. 4) and crossed the cusp region at around 07:24 UT On board, the SSJ/4 instrument records the ions' and electrons' energy spectra. The data between 07:20 and 07:27 UT are shown on Fig. 5. Plotted in the figure are, from top to bottom, (1) the integrated number flux of precipitating electron and ions, (2) the average energy of electrons and ions, (3) the differential energy flux of electrons, (4) the differential energy flux of ions, and (5) the horizontal component of the cross track convective drift.

The first three upper panels allow us to determine accurately the open/closed field lines boundary. At 07:25:20UT, we have simultaneously a dropout in magnetosheath energy electrons and the appearance of high-energy electrons precisely at 07:25:20 UT. This means that F13 flies through open field lines before 07:25:20 UT. A first glance at the third panel, the ion spectrogram, indicates that a region of magnetosheath-like ion population is crossed between 07:22:40 and 07:25:20 UT. In this same region, low energy electron precipitate, as we have just seen. This region is thought to be the cusp region, although there are several unusual features. Electron average energies are a bit higher than typical of the cusp, although this may be partly due to winter conditions. Cusp average energies are higher but fluxes are lower in winter (Newell et al., 1988). Also typically, the high-energy ions drop out in the cusp, but that does not happen here. Despite the somewhat higher electron average energy and the high-energy ions, the ion spectra are definitely cusp/magnetosheath, peaking at about $10^{8} \mathrm{eV} / \mathrm{cm}^{2} / \mathrm{s} / \mathrm{str}$ at around $1 \mathrm{keV}$.

The F13 trajectory makes the interpretation of the shape of ion spectra in the cusp difficult. Even if geographically it flies clearly from north to south, in terms of magnetic latitudes, this Southward motion is not so clear. However, there are two different regions of cusp-like precipitating particles. The first cusp crossing would be between 07:22:40 and 07:23:50 UT and the second between 07:23:50 and 07:25:20 UT, approximately. Note that the higher latitude cusp is crossed at virtually constant MLAT (75.9 most of the way through, and 76.0 at the end). This constant latitude could account for the nonexistent dispersion. Likewise, when moving though the lower latitude cusp, the latitude does change, so the dispersion is easier to see.

Nonetheless, a very interesting feature is that there is reverse dispersion at the poleward edge of the higher latitude cusp, and it is hard to see how actual reverse dispersion could occur except through high-latitude merging. Figure 5 also shows the convection velocity parallel (positive along the track and in the direction of travel) and perpendicular (positive to the left when facing forward in the direction of travel) to the spacecraft track. Knowing the orbit, the velocity across the track is, in fact, the sunward/anti-sunward component of the convection. This is true as long as the spacecraft travels at more or less constant magnetic latitude. The convection is actually sunward (positive cross-track velocity) when the reversed dispersion is recorded. However, the cross track velocity is no longer the sunward/anti-sunward velocity later on. The positive cross track velocity observed, together with the second ion dispersion, is not necessarily a sunward flow, but rather a strong eastward flow.

The velocity recorded along the path is in the opposite direction of the actual satellite motion and has a much higher typical value than the cross track velocity. This obviously means that the plasma flow is predominantly eastward, which is consistent with the dawnward IMF. 


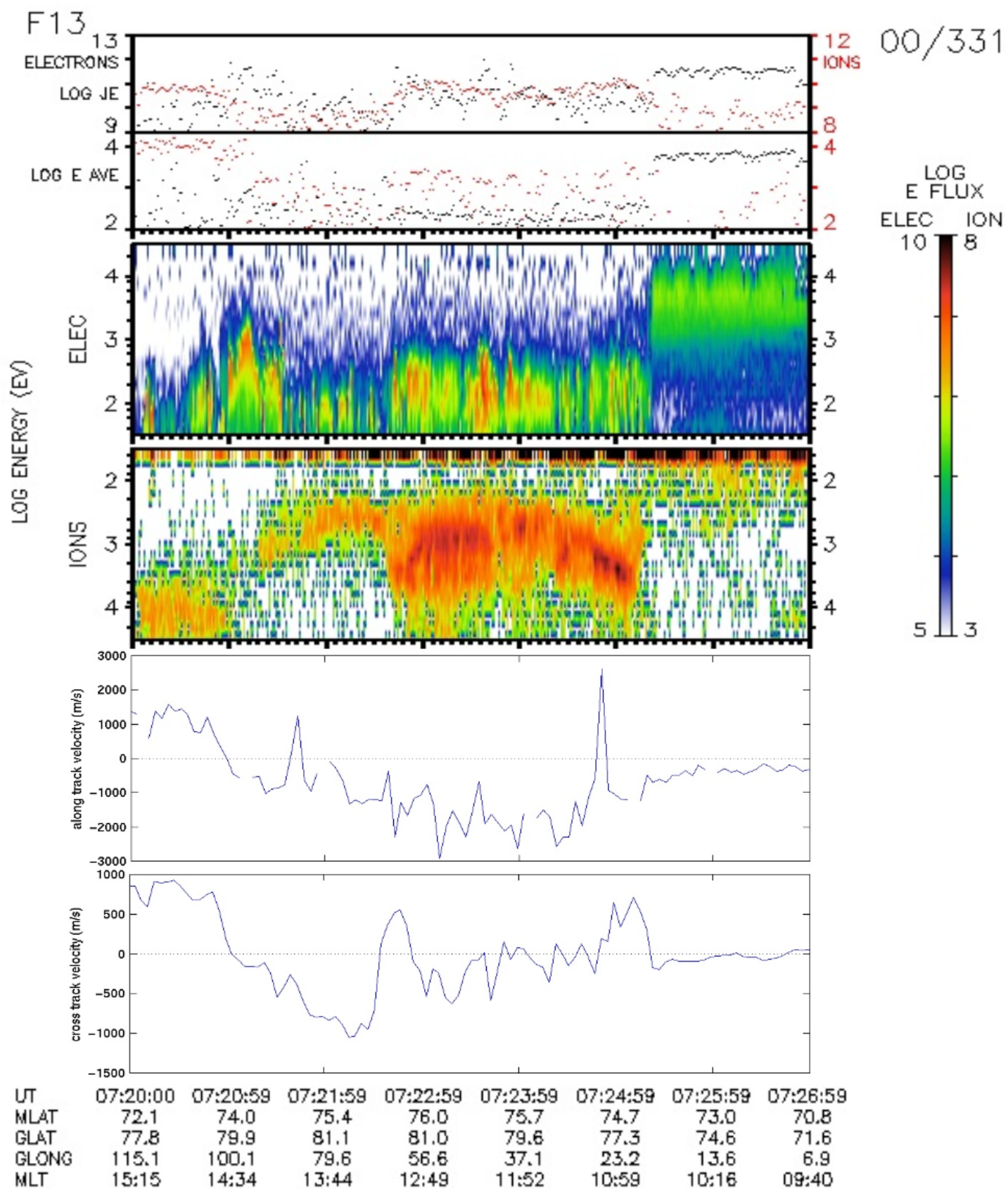

Fig. 5. Ion and electron data from SSJ/4 instrument on board DMSP-F13 spacecraft.

\section{Interpretation}

From the radars' point of view, it looks like the structures recorded by the field-aligned dish are the same observed later on by the steerable dish, at least for two of them. This is not a new feature. It has been reported recently that structures of enhanced electron density and temperature associated with pulsed reconnection may be observed by both ESR dishes, as they propagate poleward through the successive fields of view of the radars (Lockwood et al., 2001). Unlike the day described by Lockwood et al. (2001), on 26 November 2000, the IMF is far from being steadily southward. In fact, it is predominantly northward with some southward flips. The reconnection is, therefore, expected to be more sporadic rather than pulsed with a fixed period. The most surprising feature here is that the sunward flow does not decay at all during those events. Also, to complete the story, the two first flow channels at 07:05 and 07:25 UT are very well consistent in time and direction with the Hall current intensifications observed by IMAGE magnetometers. This indicates that the $\mathrm{X}$-line is actually south of Longyearbyen and the events observed by the two ESR dishes are indeed the same.

One may expect lobe reconnection for northward IMF, even if in our case the conditions are not particularly favor- 


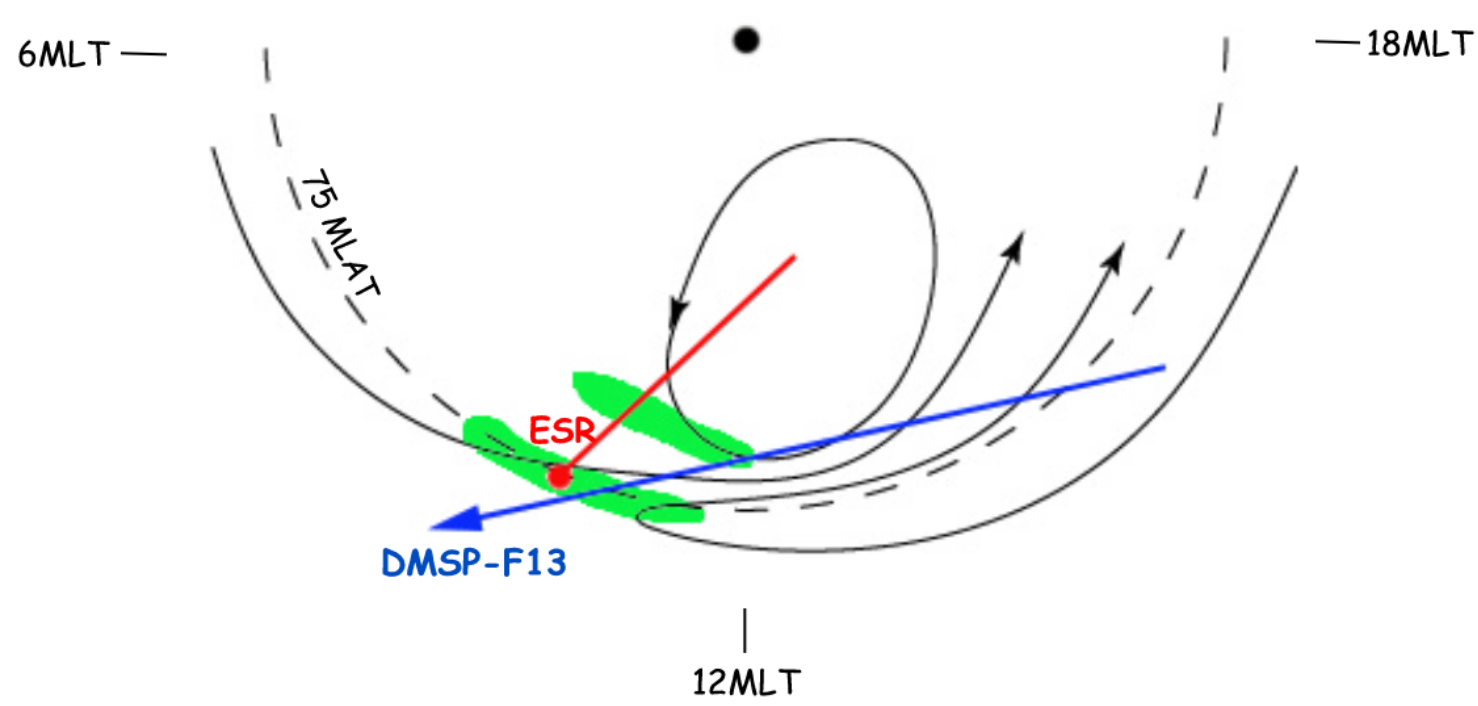

Fig. 6. Schematic of the dayside polar ionosphere around 07:25 UT showing the plasma flow in black, the EISCAT Svalbard Radars in red, the DMSP-F13 projected orbit in blue as well as the two cusp regions in green.

able (winter hemisphere). Nonetheless, the northward pointing ESR dish does observe sunward plasma flow in the cusp, which is characteristic for northward IMF (Crooker, 1992; Milan et al., 2000; Pitout et al., 2001). However, the same dish also observes what look like transient northward flow bursts. This is what we usually observe for southward IMF, when pulse reconnection takes place at the dayside magnetopause. Besides, the structures seen by the steerable antenna appear to be the same as those observed earlier and at lower latitude by the field-aligned fixed dish. These radar observations are, therefore, consistent with the idea that reconnection takes place at both low-altitude and high-latitude magnetopause.

Optical data coming from Longyearbyen station are available for this day. Unfortunately, due to cloudy conditions, the quality of those data is not good enough to be shown here. Nevertheless, the Meridian Scanning Photometer (MSP) seems to have recorded two distinct regions of cusp auroral activity (red line at $630 \mathrm{~nm}$ ). This supports our hypothesis.

Finally, although the F13 spacecraft does not pass exactly over the ESR, particle data from the SSJ/4 instruments also supports and confirms our simultaneous low-/high-latitude reconnection scenario. The "reverse" ion dispersion, together with the sunward convection recorded at high-latitude $\left(82^{\circ} \mathrm{GL}\right)$, can hardly be explained in some other way than a reconnection site located in the lobe of the magnetosphere, poleward of the cusp. Luckily, the DMSP pass occurs around 07:25 UT, precisely when a flow channel is observed at ESR and the associated Hall current intensification is recorded at the LYR IMAGE station. These observations are very consistent with each other. The very high latitude undergoes a lobe reconnection driven sunward convection, with precipitation of solar wind particles captured in the high-latitude magnetosheath. On the other hand, at lower latitudes, be- low $82^{\circ} \mathrm{GL}$, the ionosphere is subject to poleward moving transients due to reconnection at the low-latitude sub-solar magnetopause.

\section{Discussion}

Even though it is clear in this case that there exist two reconnection sites at the magnetopause, we would like to discuss here the conditions leading to this. Actually, if one closely examines the ACE data, the poleward moving transients observed by ESR correspond to somewhat different IMF conditions. Even allowing for an error in the time lag, it appears that the first flow channel occurs while the IMF still points southward but mainly dawnward. These are the typical conditions described by Wing et al. (2001) for having a double cusp. We do in fact have a double cusp here, since the high-latitude flow is already strongly sunward at this time ( 07:08 UT).

When the second flow channel is recorded at ESR and IMAGE, the IMF seems to be strongly southward for a few minutes. It is not surprising to obtain reconnection at the subsolar magnetopause here, but the sunward flow in the very highlatitude ionosphere remains. The southward excursion of the IMF is very likely not long enough to switch off reconnection in the lobe and reverse the convection.

The third flow channel is recorded neither by the fieldaligned ESR dish nor by IMAGE station in Longyearbyen (LYR). This would suggest that the open/closed field line boundary (X-line) is north of Longyearbyen. This is confirmed somewhat if one draws an oblique line in Fig. 2, such as was done for the two first channels. This line would intersect the Longyearbyen latitude $\left(78.20^{\circ} \mathrm{GL}\right)$ before the second flow channel, which cannot be correct. It should be noted that IMAGE data records a very small deviation in the $X$ - 
component that could possibly be due to the edge of the Hall current intensification associated with this third flow channel. On the other hand, the $Y$-component does not show any significant signature.

A large $Y$-component of the IMF is usually considered capable of producing reconnection at two different locations on the magnetopause. We do have a relatively large IMF $B_{y}$ compared to $B_{z}$ throughout the hour studied here. The combination of the two gives a stable clock angle at around $50^{\circ}$. Having said that, it is difficult to assert in our case that such a value is high enough to trigger a double cusp. It does seem that the short southward incursions of the IMF are a more probable explanation for having two reconnection sites simultaneously.

Theoretical studies of ionospheric convection in the polar cap for several IMF orientations were performed by Reiff and Burch (1985). This study shows that in our case, i.e. northward and dawnward IMF, at least one lobe cell is expected to develop in the afternoon sector. This implies that the plasma must be flowing eastward in the low-latitude cusp and sunward in the high-latitude cusp. This is exactly what we have seen in our data. We have to emphasize two points, though. The fact that the steerable ESR dish was pointing towards the geographic pole ( $24^{\circ}$ east of magnetic pole) allows for the observation of the modulation of the mainly eastward flow in the low-latitude cusp and, therefore, the flow channels. Second, even if the lobe cell is supposed to be located or rather centered in the afternoon sector, the steerable ESR antenna does observe sunward flow in the morning sector. Even if the antenna points towards the east, it is clear here that the lobe cell's westernmost edge (sunward flow region) is observed near noon in the morning sector (around 11:00 MLT).

The possibility of having two regions of reconnected field lines was already suggested by Weiss et al. (1995). This implies a complex plasma flow and FAC system in the cusp region. Such a configuration has been sketched in details by Sandholt et al. (1998b) for a northward and strongly duskward IMF. The larger lobe cell is then located in the morning sector and the plasma flow in the low-latitude cusp region is westward. On 26 November 2000, the IMF points dawnward $\left(B_{y}<0\right)$ most of the time. Therefore, the sketch by Sandholt et al. (1998b) has to be inverted, with the biggest lobe cell being in the afternoon sector and the plasma flowing eastward in the low-latitude cusp region. In both cases, the plasma flows southward (anti-sunward) within the highlatitude cusp. Figure 6 summarizes what we have presented in this paper. It shows the plasma flows, as expected, and as it actually fits our observations, as well as the ESR field of view, the DMSP-F13 track and the two regions of magnetosheath particle precipitations.

\section{Conclusion}

We have reported an observation of a unique case of the ionospheric response to reconnection taking place simultaneously at the dayside low-altitude magnetopause and high-latitude magnetospheric lobe. Our interpretation relies on both ESR data, which shows strong sunward and anti-sunward flows along the line-of-sight (northward pointing dish) and on a fortunate DMSP overflight of the Svalbard surroundings. The data sets are fully consistent with each other. We only regret that no optical data were good enough to be used properly in this study. In particular, an all-sky camera would have been valuable in order to have the zonal dynamics of this event.

The predominantly northward IMF conditions were obviously favorable for having lobe reconnection. On the other hand, the short southward excursions of the IMF were seen to produce flow channels, thanks to low-latitude reconnection. Even during these events, reconnection in the high-latitude lobe did not stop.

We have demonstrated in this study that the observed flow channels correspond to actual short southward IMF period. More surprising, on the other hand, is that not only the sunward flow remains even during those periods of southward IMF, but also two dispersed ion structures are observed almost simultaneously by DMSP F13 during one of those southward incursion of the IMF. This is very likely due to the short duration of those southward incursions of the IMF. They are, in fact, long enough to trigger reconnection at the low-latitude magnetopause, but apparently short enough not to switch off reconnection in the lobe.

A more in-depth study with simulation of the dayside ionosphere experiencing the effects of two cusp-like particle precipitations regions and their corresponding oppositely directed plasma flows would be of high interest. Such a study would undoubtedly help to improve our understanding of the ionosphere response to this complex configuration, namely two X-lines.

Acknowledgements. The authors are grateful to the director and staff of the EISCAT Scientific Association for providing the radar facilities and assistance with making the observations. EISCAT is an international association, supported the research councils of Finland, France, Germany, Japan, Norway, Sweden and the United Kingdom. We thank the institutes, which maintain the IMAGE magnetometers array. The IMAGE magnetometer data are collected as a Finnish-German-Norwegian-Polish-Russian-Swedish project. DMSP driftmeter data were provided by Marc Hairston at Center for Space Sciences, University of Texas at Dallas. We thank the Situation Satellite Center (SSC Web) for satellites orbits. We are grateful to R. Fujii for allowing us to use ESR data taken as Japanese Special Program.

Topical Editor M. Lester thanks P. E. Sandholt and another referee for their help in evaluating this paper.

\section{References}

Chandler, M. O., Fuselier, S. A., Lockwood, M., and Moore, T. E.: Evidence of component merging equatorward of the cusp, J. Geophys. Res., 104, 22 623-22 634, 1999.

Crooker, N. U.: Reverse convection, J. Geophys. Res., 97, 19363$19372,1992$. 
Fuselier, S. A., Trattner, K. J., and Petrinec, S. M.: Cusp observations of high- and low-latitude reconnection for northward interplanetary magnetic field, J. Geophys. Res., 105, 253-266, 2000.

Lockwood, M., Opgenoorth, H., Van Eyken, A. P. et al.: Coordinated Cluster, ground-based instrumentation and low-latitude satellite observations of transient poleward-moving events in the ionosphere and tail lobe, Annales Geophysicae, 19, 1589, 2001.

McCrea, I. W., Lockwood, M., Moen, J., Pitout, F., Eglitis, P., Aylward, A. D., Cerisier, J.-C., Thorolfssson, A., and Milan, S. E.: ESR and EISCAT observations of the response of the cusp and cleft to IMF orientation changes, Ann. Geophysicae, 18, 10091026, 2000.

Milan, S. E., Lester, M., Cowley, S. W., and Brittnacher, M.: Dayside convection and auroral morphology during an interval of northward interplanetary magnetic field, Ann. Geophysicae, 18, 4, 436-444, 2000.

Newell, P. T. and Meng, C.-I.: Hemispherical asymmetry in cusp precipitation near solstices, J. Geophys. Res., 93, 2643-2648, 1988.

Øieroset, M., Sandholt, P. E., Denig, W. F., and Cowley, S. H. W.: Northward interplanetary magnetic field cusp aurora and highlatitude magnetopause reconnection, J. Geophys. Res., 102, 11 349-11362, 1997.

Pitout F., Bosqued, J.-M., Alcaydé, D., Denig, W. F., and Rème, H.: Observation of the cusp region under northward IMF, Ann. Geophysicae, 19, 1641-1653, 2001.

Pryse, S. E., Smith, A. M., Kersley, L., Walker, I. K., Mitchell, C. N., Moen, J., and Smith, R. W.: Multi-instrument probing of the polar ionosphere under steady northward IMF, Ann. Geophysicae, 18, 1, 90-98, 2000.

Reiff, P. H. and Burch, J. L.: IMF $B_{y}$-dependent plasma flow and Birkeland currents in the dayside magnetosphere. 2. A global model for Northward and Southward IMF, J. Geophys. Res., 90, 1595-1609, 1985.

Russell, C. T., Le, G., and Petrinec, S. M.: Cusp observations of high- and low-latitude reconnection for northward IMF: an alternate view, J. Geophys. Res., 105, 5489, 2000a.

Russell, C. T.: The polar cusp, Coordinated measurements of magnetospheric processes, 25, 1413, 2000b.

Sandholt, P. E., Farrugia, C. J., Moen, J., Noraberg, Ø., Lybekk, B., Sten, T., and Hansen, T.: A classification of dayside auroral forms and activities as a function of IMF orientation, J. Geophys. Res., 103, 23 325-23 346, 1998a.

Sandholt, P. E., Farrugia, C. J., Moen, J., Cowley, S. W. H., and Lybekk, B.: Dynamics of the aurora and associated convection currents during a cusp bifurcation event, Geophys. Res. Lett., 25, 4313, $1998 b$.

Sandholt, P. E., Farrugia, C. J., and Cowley, S. W. H.: Pulsating cusp aurora for northward interplanetary magnetic field, J. Geophys. Res., 103, 26 507-26 520, 1998c.

Sandholt, P. E., Farrugia, C. J., Cowley, S. W. H., Denig, W. F., Lester, M., Moen, J., and Lybekk, B.: Capture of magnetosheath plasma by the magnetosphere during northward IMF, Geophys. Res. Lett., 26, 2388, 1999.

Sandholt, P. E., Farrugia, C. J., Cowley, S. W. H., and Lester, M.: Dayside auroral bifurcation sequence during $B_{y}$-dominated interplanetary magnetic field: Relationship with merging and lobe convection cells, J. Geophys. Res., 106, 15 429-15 444, 2001.

Smith, M. F. and Lockwood, M.: Earth's magnetospheric cusps, Reviews of Geophysics, 34, 2, 233-260, 1996.

Song, P., DeZeeuw, D. L., Gombossi, T. L., Groth, C. P., and Powell, K. G.: A numerical study of solar wind-magnetosphere interaction for northward interplanetary magnetic field, J. Geophys. Res., 104, $28361,1999$.

Song, P., Gombossi, T. I., DeZeeuw, D. L., Powell, K. G., and Groth, C. P.: A model of solar wind-magnetosphere-ionosphere coupling for due northward IMF, Planet. Space Sci., 48, 29, 2000.

Thorolfsson, A., Cerisier, J.-C., Lockwood, M., Sandholt, P. E., Senior, C., and Lester, M.: Simulataneous optical aurora and radar signatures of polar-moving auroral forms, Ann. Geophysicae, 18, 1054-1066, 2000.

Viljanen, A. and Häkkinen, L.: IMAGE magnetometer network, in: Satellite-Ground Based Coordination Sourcebook, (Eds) Lockwood, M., Wild, M. N. and Opgenoorth, H. J., ESA publications SP-1198, 111-117, 1997.

Weiss, L. A., Reiff, P. H., Weber, E. J., Carlsson, H. C., Lockwood, M., and Peterson, W. K.: Flow-aligned jets in the magnetospheric cusp: Results from the Geospace Environment Modeling Pilot program, J. Geophys. Res., 100, 7649-7659, 1995.

Wing, S., Newell, P. T., and Ruohoniemi, J. M.: Double Cusp: Model Prediction and Observational Verification, J. Geophys. Res., 106, 25 571-25 594, 2001. 